\title{
Lipid Profile of the Coronary Heart Disease (CHD) Patients Admitted in a Hospital in Malaysia
}

\author{
ATM Emdadul Haque ${ }^{1 *}$, Fatimah Binti Mohammed Yusoff ${ }^{1}$, Mohd Haidir Syawalstri Bin Ariffin ${ }^{1}$, Muhammad Fadhli \\ Bin Ab Hamid ${ }^{1}$, Siti Raihana Binti Hashim¹, Mainul Haque ${ }^{2}$ \\ ${ }^{1}$ Faculty of Medicine, Universiti Kuala Lumpur Royal College of Medicine Perak, 30450 Ipoh, Perak, Malaysia. ${ }^{2}$ Unit of Pharmacology, Faculty of \\ Medicine and Defense Health, National Defence University of Malaysia, Kem Sungai Besi, 57000 Kuala Lumpur, Malaysia.
}

\begin{tabular}{l} 
ARTICLE INFO \\
\hline Article history: \\
Received on: $11 / 12 / 2015$ \\
Revised on: 03/01/2016 \\
Accepted on: 10/02/2016 \\
Available online: $28 / 05 / 2016$ \\
\hline Key words: \\
Coronary heart disease, lipid \\
profile, risk factors.
\end{tabular}

\begin{abstract}
Coronary Heart Disease refers to a group of closely related syndrome caused by imbalance between the myocardial oxygen demand and the blood supply. It is the single most common cause of death in economically developed countries, including the United States and Europe. Hypercholesterolemia is considered as one of the most common modifiable risk factors of CHD. Men are more commonly affected than women until the fifth decade, after which time the frequency of CHD is similar in both sexes. Other risk factors are hypertension, diabetes mellitus, and smoking. This was a cross-sectional study in demonstrating the pattern of the lipid profile (Total Cholesterol (TC); Low Density Lipoprotein (LDL-C); High Density Lipoprotein (HDL-C) and Triglyceride levels (TG) among the CHD patients admitted in the hospital. Most of the CHD patients had the total cholesterol level high, and among them $25.6 \%$ were Malay. Malays were the highest in the optimal range (< $3.0 \mathrm{mmol} / \mathrm{L}$ ) with $20.9 \%$ and HDL level within the normal range $(1.2-1.8 \mathrm{mmol} / \mathrm{L})$ by $22.2 \%$ (34). Most of the CHD patients had the TG level within normal range $(<1.5 \mathrm{mmol} / \mathrm{L})$ but among them $19.9 \%$ were Malays. This study had demonstrated that Malays were mostly affected by heart disease (HD) followed by Chinese and Indians, and the incidence was twice as high as in men compared to women.
\end{abstract}

\section{INTRODUCTION}

Coronary heart disease (CHD) is a leading cause of morbidity and mortality in many countries world-wide and is estimated that it will be the single largest cause of disease burden (WHO, 2015). CHD can develop at any age. It refers to a group of closely related syndromes caused by an imbalance between the myocardial oxygen demand and the blood supply. Depending on the rate severity of coronary artery narrowing and the myocardial response, one of four syndromes may develop: angina pectoris (chest pain), acute myocardial infarction, sudden cardiac death and chronic ischemic heart disease with congestive heart failure (Kumar et al., 2015). The most common cause of CHD is narrowing of the lamina of the coronary arteries by atherosclerosis. Initially, an area of atheromatous plaque forms in the coronary artery. The mechanism for plaque formation is

\footnotetext{
* Corresponding Author

ATM Emdadul Haque, Faculty of Medicine, Universiti Kuala Lumpur Royal College of Medicine Perak, 30450 Ipoh, Perak, Malaysia.

Email:emdad0103@gmail.com
}

unclear, although the predominant view is that lipid accumulates under the lining of the coronary artery. Because the lipid infiltrate is a foreign matter, white blood cells called macrophages engulf it, and create foam cells. Smooth muscle cells then invade the area, which enlarges the plaque and obstructs more than $50 \%$ of the lumen of the coronary artery that the flow of blood to the heart muscle, the myocardium, is reduced (Kumar et al., 2015; Burke et al., 1997); while resting, or undertaking a minimal activity, the blood supply to the heart is adequate. However, when the heart requires a greater supply of oxygen, as occurs during exercise or emotional episodes, the blood supply cannot increase sufficiently and the person will experience chest discomfort. This is referred to as angina pectoris. Once plaque has formed, the wall of the coronary artery is damaged and irregular in shape and platelets cluster around the obstruction. This reduces the size of the lumen still further and consequently the blood supply is also reduced (Kumar et al., 2015). A number of factors are thought to increase the likelihood of developing CHD. It can be divided into two, which are controllable and uncontrollable risk factors. 
Controllable risk factors are hypertension, hypercholesterolemia, smoking, obesity, sedentary lifestyle, diabetes, stress, hyperhomocysteinemia, depression and anxiety. However, uncontrollable risk factors are gender, heredity and age (Milinow, 1990; Bostom et al., 1999; Kuulasmaa et al., 2000; Lee et al., 2001; D'Agostino et al., 2000; ESCHDCRG, 1998; Karim et al., 2000; O'Malley et al., 2000). Despite a lot of investigation for novel risk factor, established risk factors still play a major role for CVD (Kuulasmaa et al., 2000). These are the dyslipidemias including high, low density lipoprotein cholesterol (LDL-C), low, high density lipoprotein cholesterol (HDL-C) and high fasting triglyceride (TG), hypertension, cigarette smoking, diabetes, obesity and physical inactivity (Lee et al., 2001; D'Agostino et al., 2000; ESCHDCRG, 1998). The objective of this study was to assess the lipid profiles of the CHD patients admitted in Hospital Raja Permaisuri Bainun (HRPB) Ipoh, Malaysia.

\section{MATERIALS AND METHODS}

This was a cross-sectional descriptive study done during the period of 01-10-2013 to 31-12-2013. All the demographic and risk factors related information were collected from the patient's record available in the hospital. A data collection sheet was designed to gather all the necessary information of the patients. The written official permission was taken from the Hospital Director through the Elective coordinator. The data was then analyzed by using standard statistical program, SPSS version 16 . Blood lipids were categorized into total cholesterol, LDL-C, HDL$\mathrm{C}$ and TG levels. Total cholesterol was further categorized into desirable $(<4 \mathrm{mmol} / \mathrm{L})$, borderline high $(4-4.8 \mathrm{mmol} / \mathrm{L})$ and high $(>4.8 \mathrm{mmol} / \mathrm{L})$. LDLc was further classified into optimal $(<3$ $\mathrm{mmol} / \mathrm{L})$, near optimal (3 - $3.9 \mathrm{mmol} / \mathrm{L})$, borderline high (4 - 4.8 $\mathrm{mmol} / \mathrm{L})$ and high $(>4.8 \mathrm{mmol} / \mathrm{L})$. For HDLc, it was divided into 3 groups which were heart disease risk factor $(<1.2 \mathrm{mmol} / \mathrm{L})$, normal range $(1.2-1.8 \mathrm{mmol} / \mathrm{L})$ and lower risk of heart disease $(>1.8$ $\mathrm{mmol} / \mathrm{L})$ whereas for TG level, it was divided into normal $(<1.5$ $\mathrm{mmol} / \mathrm{L})$, borderline high $(1.5-2 \mathrm{mmol} / \mathrm{L})$ and high $(>2 \mathrm{mmol} / \mathrm{L})$ (Figure 5). Smoking status was grouped into the smoker, exsmoker and non-smoker. History of diabetes was classified into diabetic and non-diabetic. Diabetics were people who previously diagnosed and on treatment or with plasma glucose $\geq 11.1 \mathrm{mmol} / \mathrm{L}$ after oral glucose tolerance test. A family history of CHD was defined as close (first) relatives who suffered from CHD. All of the $160 \mathrm{CHD}$ patients admitted in the hospital during the period of October 01 to December 31, 2013 were included.

\section{RESULTS}

160 patients aged between 30 to 79 years were included in this study (Figure 1). Out of 160 patients with CHD, 69\% were male and $31 \%$ female (Figure 2). The ethnic distribution of the patients were $48 \%$ Malay, 32\% Indians, 19\% Chinese and 1\% others respectively (Figure 3). 50\% of the patients had a high total cholesterol level $(>4.8 \mathrm{mmol} / \mathrm{L})$ and $29 \%$ had borderline total cholesterol levels (4.0 - $4.8 \mathrm{mmol} / \mathrm{L})$ (Figure 4). Only $20 \%$ of the patients had a desirable total cholesterol level $(<4.0 \mathrm{mmol} / \mathrm{L})$. Among the study patients, $48 \%$ had optimal ( $<3.0 \mathrm{mmol} / \mathrm{L}), 34 \%$ had nearly optimal $(3.0$ - $3.9 \mathrm{mmol} / \mathrm{L}), 7 \%$ had borderline $(4.0$ $4.8 \mathrm{mmol} / \mathrm{L})$ and $9 \%$ ) had high (>4.8 $\mathrm{mmol} / \mathrm{L})$ level of LDL-C respectively. $48 \%$ had normal $(1.2-1.8 \mathrm{mmol} / \mathrm{L}), 41 \%$ had lower $(<1.2 \mathrm{mmol} / \mathrm{L})$ and $8 \%$ had higher $(>1.8 \mathrm{mmol} / \mathrm{L})$ level of HDL-C respectively. $41 \%$ had normal $(<1.5 \mathrm{mmol} / \mathrm{L}), 31 \%$ had high $(>2.0$ $\mathrm{mmol} / \mathrm{L})$ and $28 \%$ had borderline high $(1.5-2.0 \mathrm{mmol} / \mathrm{L}) \mathrm{TG}$ level respectively.

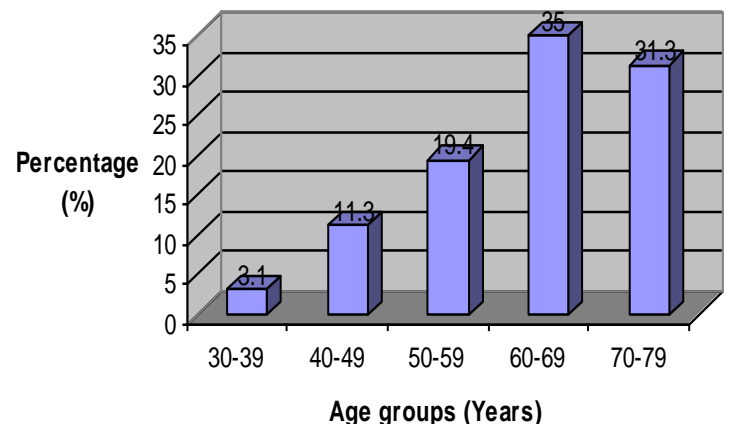

Fig. 1: Distribution of CHD cases according to age groups.

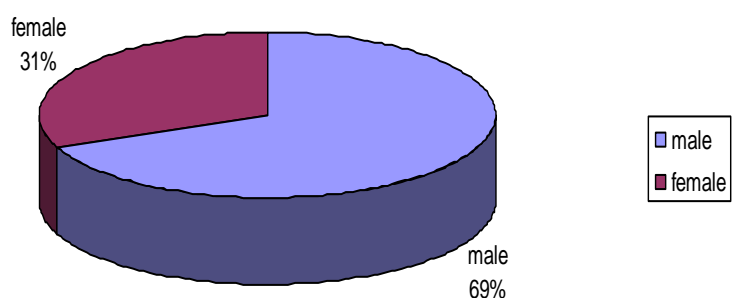

Fig. 2: Distribution of CHD cases according to gender.

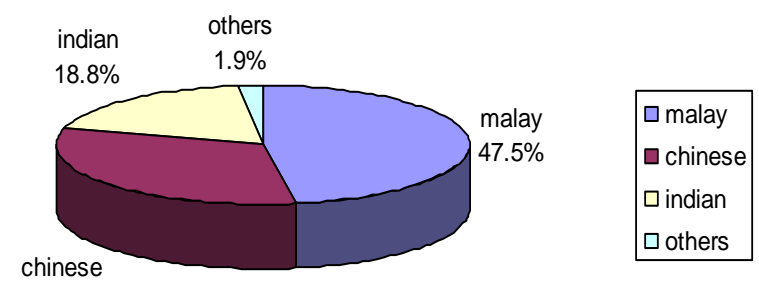

$31.9 \%$

Fig. 3: Distribution of CHD cases according to ethnicity.

$54 \%$, of the patients had high $(>140 \mathrm{~mm} \mathrm{Hg}), 44 \%$ had normal $(100-140 \mathrm{~mm} \mathrm{Hg})$ and $2 \%$ had low $(<100 \mathrm{~mm} \mathrm{Hg})$ systolic blood pressure respectively. On the other hand, $68 \%$ had normal (60 - $90 \mathrm{~mm} \mathrm{Hg}), 29 \%$ had high (>90 $\mathrm{mm} \mathrm{Hg}$ ), and $3 \%$ had low $(<60 \mathrm{~mm} \mathrm{Hg})$ diastolic blood pressure respectively. Surprisingly $46 \%$ of the study population were smoker, $31 \%$ nonsmoker and $23 \%$ were ex-smoker respectively, and $57 \%$ were diabetic and $43 \%$ were non-diabetic. Only $61 \%$ of the patients had a family history and $31 \%$ had no family history of CHD (Figure 6). Among the study population, $51 \%$ had high total cholesterol level; $50 \%$ had the LDL-C level within the optimal range $(<3.0 \mathrm{mmol} / \mathrm{L})$; and $41 \%$ had the TG level within normal range $(<1.5 \mathrm{mmol} / \mathrm{L})$. Among the $51 \%$ patients with high total cholesterol level, male were $33 \%$ and female were $18 \%$; and $26 \%$ of them were Malay population. 
Distribution of total cholesterol among CHD patients

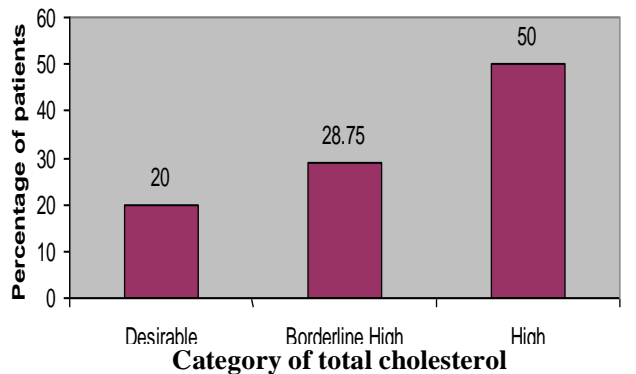

Distribution of HDL level among CHD patients

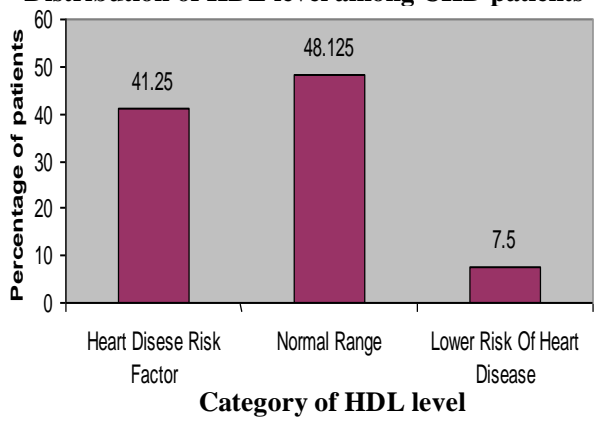

Fig. 4: Level of Total Cholesterol, LDLC, HDLC And TG among CHD Patients.

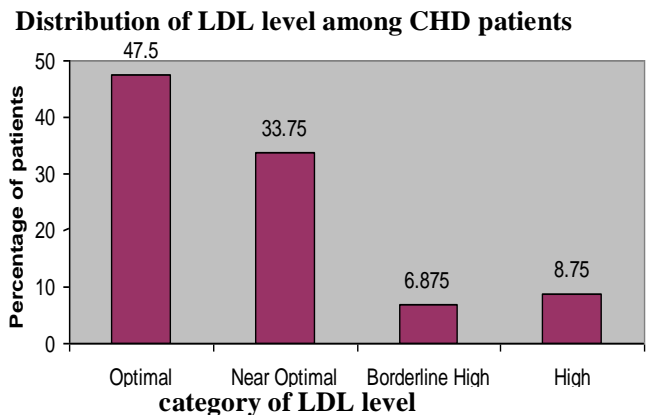

Distribution of trigly ceride level among CHD patients

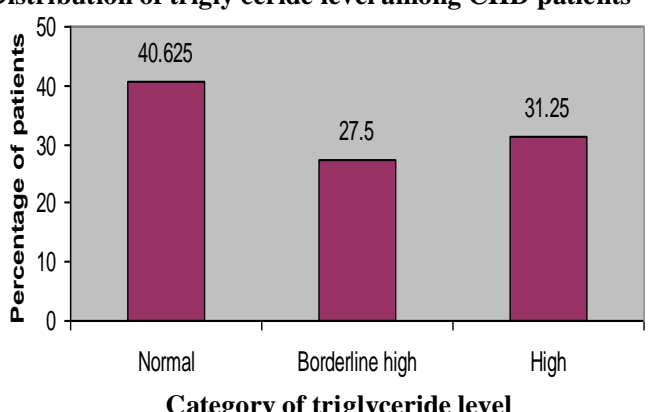

Category of triglyceride level
Distribution of systolic blood pressure among CHD patients

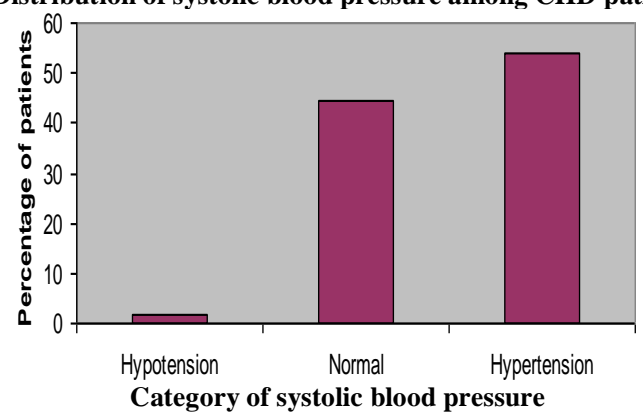

Distribution of smoking status among CHD patients

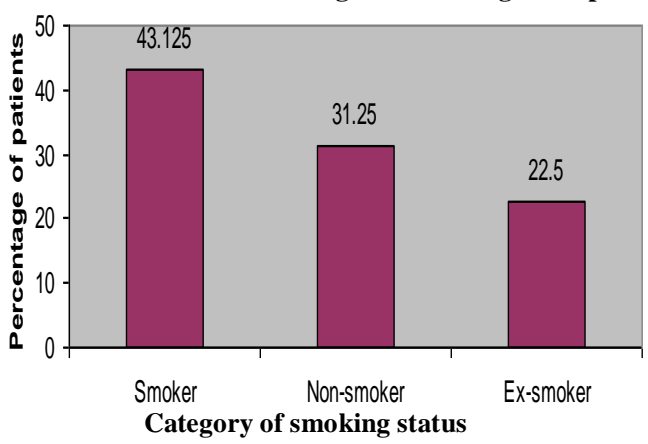

Distribution of diastolic blood pressure among CHD patients

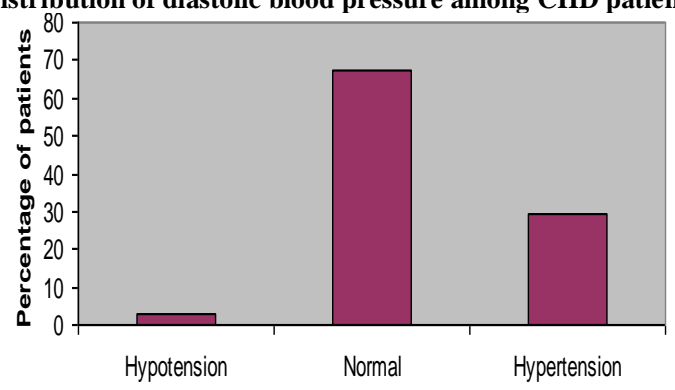

Category of diastolic blood pressure

Distribution of history of diabetic among CHD patients

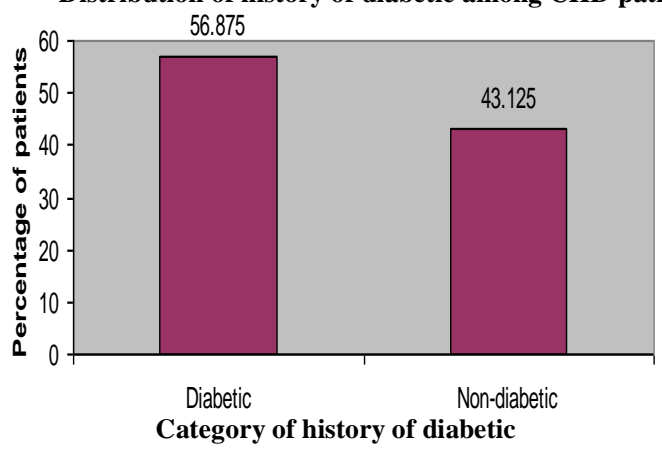

Category of history of diabetic

Fig. 5: Distribution of risk factor among the CHD patients.

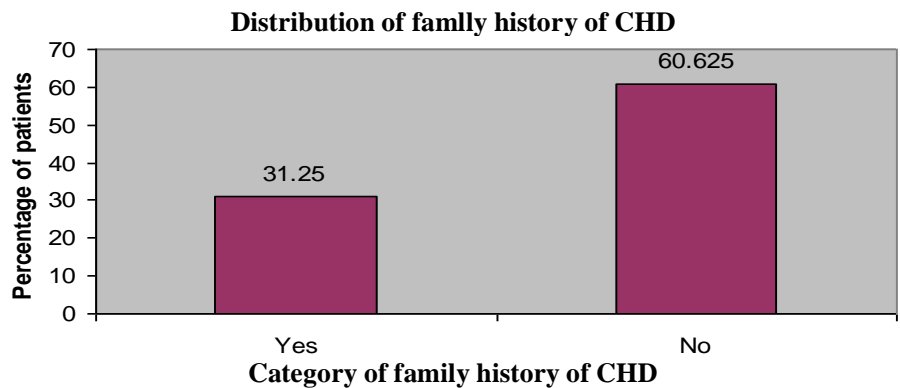

Fig. 6: Distribution of Family History of CHD patients 


\section{DISCUSSION}

In this study, $35 \%$ of the patients were from the age group of 60-69 years and the lowest number was from 30-39 years group. Age is a dominant feature, and death rates from the CHD rise with decade, even into advanced age (Institute of Medicine, 2010; Gaziano et al., 2006). Arteriosclerosis is not clinically evident until middle age or later, when the arterial lesions precipitate the organ injury (Alarabawy et al., 2015). The incidence of myocardial infarction increase fivefold between the age ranging from 40-60 (Bui et al., 2011; Ganesh et al., 2013). Our study found that the highest percentage was represented by the Malay population. $47.5 \%$ patients were Malay; followed by $14.74 \%$ (Chinese), $18.8 \%$ (Indians) and the remaining $1.9 \%$ were from other ethnicities. This finding differed from another Malaysian study where it was found that Indians had the highest CHD mortality (51.8 per 100 000) followed by Chinese (26.5) and Malays (14.4) (Geok, 1994). Thus, Indians have a CHD mortality risk which twice that for Chinese and 3.6 times higher than that for Malays. This difference could be due to the smaller sample size in this study. The prevalence of male CHD patient was twice as high as women, 110 and 50 respectively in the current study. This finding is comparable with another Malaysian research study that reported the rate was 27.2 per 100000 for men and 13.6 for women (Khor, 1994). In addition, men are much prone to develop atherosclerosis and its consequences than women (Institute of Medicine, 2010; Maas and Appelman, 2010).

When comparing the prevalence of atherosclerosis for men and women, according to two age categories, 30-39 and 60-69 respectively, women in 60-69 age group showed eight times higher and men 16 times higher than 30-39 age group. Myocardial infarction and other complication of atherosclerosis are uncommon in premenopausal women. However, the incidence of atherosclerosis-related disease increases, probably owing to a decrease in natural estrogen levels (LaRosa, 1992; Tanna et al., 2013). Indeed, the frequency of myocardial infarction in both sexes equalizes by the seventh to eighth decade of life (Kumar et al., 2010). This study findings regarding the frequency of men and women in two age groups were not equalized perhaps due to small sample size, and perhaps women have higher awareness for health and medical care especially when it was seen that all of them were non-smoker. Dyslipdemia is the major risk factor in the development of coronary heart disease (Institute of Medicine, 2010). The current study, we found that $50 \%$ of the samples have high total cholesterol level. However, the majority of the patients $(48 \%)$ of them had the optimal LDL level ( $<3.0 \mathrm{mmol} / \mathrm{L}), 40.6 \%$ had normal triglyceride levels $(<1.5 \mathrm{mmol} / \mathrm{L})$ and $48.12 \%$ had a normal range of HDL level $(1.2-1.8 \mathrm{mmol} / \mathrm{L})$. Importantly, this result may not have been of sufficient duration and period to show the full effect of high LDL, TG and low HDL as the risk factors because this is a retrospective cross-sectional study. The patient has been hospitalized to the Ipoh GH may had control their diet program. These findings were similar with one study from Singapore with almost same ethnic background (Lee et al., 2001).
This study found that $54 \%$ of the patients had hypertension ( $\mathrm{SBP}>140 \mathrm{mmHg})$. The prevalence of hypertension in Malaysia is between 14 - 24\% (Ministry of Health, 2013). ${ }^{21}$ It contributes to more than one third of premature mortality due to $\mathrm{CHD}$ and a greater proportion due to stroke (Yunus et al., 2004). Most of the patients $(43 \%)$ who had CHD were smokers which is comparable with a study that showed cigarette smoking as the single most prevalent risk factor of CHD patients in Malaysia (Khor, 1994; Yunus et al., 2004; Quek et al., 1989).

Majority (57\%) of the patients in this study were diabetic which is comparable with another study done in Malaysia and found that people with diabetes had a two to eight-fold more risk of developing heart disease (Khor, 1994; Martín-Timón et al., 2014). $61 \%$ of the patients had a family history of CHD whereas the other $31 \%$ had no family history of CHD. A strong family history of heart disease can increase an individual's risk for coronary heart disease fourfold, and even a moderate family history can lead to a two-fold increase in risk, a population-based study had shown (Collins, 2006; Buttar et al., 2005). The family history is considered to be significant when a male relative's first CHD event occurred before the age of 55, or a female relative's first CHD event occurred before 65 (Scheuner et al., 2008; Roncaglioni et al., 1992; Nasir et al., 2004). Some other studies had shown that death from CHD was largely influenced by genetic factors with a positive family history being associated with a $75 \%$ increase in risk in men, and an $84 \%$ increase in women (Kashani et. al., 2013; Zdravkovic et al., 2002).

The National Cholesterol education program (NCEP) of The National Heart, Lung, and Blood Institute (NHLBI) has established guidelines for the prevention and treatment of lipid disorders. According to the NCEP guidelines, all patients at least 20 years of age should have an initial cholesterol measurement. It is recommended that the initial laboratory test measure both the total and HDL cholesterol. The American Diabetes Association (ADA) recommends that diabetic patients should receive a complete lipid profile annually (Eldor and Raz, 2009; ADA, 2003; Jellinger et al., 2013). The most (51\%) of CHD patient have high total cholesterol and high prevalence in male (34\%) than female (17\%). High total cholesterol levels common in the age group between 60-69 years, and among them, TC was higher (26\%) among Malays rather than Chinese, Indian and other ethnic groups. Total cholesterol level was also high amng the Malays who suffer diabetic dyslipidemia than other races. This also shows the correlation since diabetes mellitus is one of the major risk factors for CHD. Similar observations were also found in a number of studies (Al-Harbi, 2004; Shestov et al., 1993; Castelli et al., 1977).

LDL-C level for the CHD patient are mostly (49\%) within optimal range. The highest came from age group between $70-79$ years old (18\%), among them $31 \%$ were male and $26 \%$ were Malays. Other studies among the CHD patient found that most of the patient has an LDL-C level near the optimal range and came from age group between 51-74 years old which nearly similar to our study (Bambauer et al., 2012). The cardiovascular cohort 
studies in Singapore, all the Chinese, Malay, and Asian Indian male that suffer from CHD have an LDL-C level $\geq 4.14 \mathrm{mmol} / \mathrm{L}$ (Lee et al., 2001). This is also same as our results, but we are more specific in aspect of gender and ethnicity.

This study also found that most of the CHD patients have HDL-C level within normal range and the highest percentage came from patient in age group between 60-69 years old (16\%), among them $35 \%$ were male and $22 \%$ were Malays. Another study reported that $\mathrm{CHD}$ patient had high levels of HDL-C from the age group below 25 years and the patient within the age group above 60 years usually had low levels of HDL-C (Miller and Miller, 1975). This is different from the current study that may be due to dyslipidaemia which occasionally causes the development of CHD than other risk factor for example hypertension. Multiple Malaysian research revealed that HDL values were significantly higher in females than males and much lower among the Indian males, rather than Chinese and Malay (Ng et al., 1997; Tan et al., 2011; Blebil et al., 2011). In this study, male accounts for most of the samples that might have affected the result. However, the low prevalence of CHD among the Indians may be due to the difference in their ethnic origin (Chaturvedi, 2003). The TG level among the CHD patients was in the normal range. Most of them from age group between 60-69 years (16\%), among them 32\% were male and $20 \%$ were Malays. High TG level was also demonstrated in a study among the American survivors of Myocardial Infarction (MI) (Miller et al., 2011; Jeppesen et al., 1998; Weitz et al., 2010) and most of them were female around 40-49 years old. These findings are totally different from the current study result perhaps because they just had focused on MI only. According to the study among the Malaysians who suffered coronary artery disease (CAD), the evaluation also been made on TG level, but within the patient and control group, however, no difference in TG level that could be attributed to the ethnicity ( $\mathrm{Ng}$ et al., 1997).

\section{CONCLUSION}

The findings of this study indicated high serum cholesterol as an important single risk factor for CHD and an increase in the levels of LDL-Cholesterol and a decrease in HDLCholesterol especially among the males and in Malays. There were some similarities and dissimilarities with other studies have also been shown. Therefore, there is a need to extend the study on a larger population and an urgent need for appropriate interventions to maintain the serum total cholesterol and LDL-C levels within the expected range.

\section{ACKNOWLEDGEMENT}

Authors are grateful to the Director of Hospital Raja Permaisuri Bainun, Ipoh, Perak, Malaysia for his kind approval to carry out this study. We acknowledge the support of the Head of Record Department and the hospital staff, the elective Coordinator, the staff of UniKL RCMP who helped us in many ways to carry out and complete this study.

\section{REFERENCES}

Alarabawy RA, El Ahwal HM, Elwagih MM, Ismail A, Khattab MA. Use of multi-detector CT angiography in identification and classification of aorto-iliac diseases; clinical and surgical application. The Egyptian Journal of Radiology and Nuclear Medicine, 2015. http://www.sciencedirect.com/science/article/pii/S0378603X15002041

Al-Harbi AM. Frequency of Risk Factors for Coronary Heart Disease Among Diabetic Patients in Al-Rabwah PHC Center in Riyadh. Journal of Family \& Community Medicine, 2004; 11(2):53-58.

American Diabetes Association (ADA). Standards of Medical Care for Patients With Diabetes Mellitus. Diabetes Care, 2003; 26(Suppl 1): s33-s50

Bambauer R, Bambauer C, Lehmann B, Latza R, Schiel R. Schiel R. LDL-Apheresis: Technical and Clinical Aspects. Scientific World Journal, 2012; 2012: 314283.

Blebil AQ, Hassan Y, Dujaili JA. Differences in Demographics, Lipid Profile and Other Clinical Characteristics Among Type 2 Diabetic Patients in the State of Penang, Malaysia According to Gender and Races, Asian J Pharm Clin Res, 2011; 4(Suppl 2): 130-133.

Bostom AG, Rosenberg IH, Silbershatz H, Jacques PF, Selhub J, D'Agostino RB, Wilson PW, Wolf PA. Nonfasting plasma total homocysteine levels and stroke incidence in elderly persons: the Framingham Study. Annals of internal medicine, 1999; 131(5):352-355.

Bui AL, Horwich TB, Fonarow GC. Epidemiology and risk profile of heart failure. Nature reviews Cardiology, 2011; 8(1):30-41. doi:10.1038/nrcardio.2010.165.

Burke AP, Farb A, Malcom GT, Liang YH, Smialek J, Virmani R. Coronary risk factors and plaque morphology in men with coronary disease who died suddenly. N Eng J Med, 1997; 336 (18): 1276-1282.

Buttar HS, Li T, Ravi N. Prevention of cardiovascular diseases: Role of exercise, dietary interventions, obesity and smoking cessation. Exp Clin Cardiol, 2005; 10(4): 229

Castelli WP, Doyle JT, Gordon T, Hames CG, Hjortland MC, Hulley SB, Kagan A, Zukel WJ. HDL Cholesterol and Other Lipids in Coronary Heart Disease the Cooperative Lipoprotein Phenotyping Study. Circulation, 1977; 55(5): 767-772.

Chaturvedi N. Ethnic Differences in Cardiovascular Disease. Heart, 2003; 89(6): 681-686.

Collins P. Risk factors for cardiovascular disease and hormone therapy in women. Heart, 2006; 2 (Suppl 3): iii24-iii28.

D'Agostino RB, Russell MW, Huse DM, Ellison RC, Silbershatz H, Wilson PW, Hartz SC. Primary and subsequent coronary risk appraisal: New results from the Framingham study. Am Heart J, 2000:139 (2 Pt 1):272-281.

Eastern Stroke and Coronary Heart Disease Collaborative Research Group (ESCHDCRG). Blood pressure, cholesterol and stroke in Asia. Lancet, 1998; 352 (9143):1801-1807.

Eldor R, Raz I. American Diabetes Association Indications for Statins in Diabetes. Diabetes Care, 2009; 32 (Suppl 2): S384-S391.

Ganesh M, Palaneeswari SM, Karthikeyan T. Bio-Markers Assay in Acute Myocardial Infarction- A Cross Sectional Study. Int J Pharm Bio, Sci 2013; 4(4): 1139-1142.

Gaziano T, Reddy KS, Paccaud F, et al. Cardiovascular Disease. In: Jamison DT, Breman JG, Measham AR, et al., editors. Disease Control Priorities in Developing Countries. 2nd edition. Washington (DC): World Bank; 2006. Chapter 33. Available from: http://www.ncbi.nlm.nih.gov/ books/NBK11767/

Institute of Medicine (US) Committee on Preventing the Global Epidemic of Cardiovascular Disease: Meeting the Challenges in Developing Countries; Fuster V, Kelly BB, editors. Promoting Cardiovascular Health in the Developing World: A Critical Challenge to Achieve Global Health. Washington (DC): National Academies Press (US); 2010. 2, Epidemiology of Cardiovascular Disease. Available from: http://www.ncbi.nlm.nih.gov/books/NBK45688/

Jellinger PS, Smith DA, Mehta AE, Ganda O, Handelsman Y, Rodbard HW, Shepherd MD, Seibel JA, The AACE Task Force for Management of Dyslipidemia and Prevention of Atherosclerosis. American Association of Clinical Endocrinologists Guidelines for 
Management of Dyslipidemia and Prevention of Atherosclerosis. AACE Guidelines. 2013. https://www.aace.com/files/lipid-guidelines.pdf

Jeppesen J, Hein HO, Suadicani P, Gyntelberg F. Triglyceride Concentration and Ischemic Heart Disease An Eight-Year Follow-up in the Copenhagen Male Study. Circulation, 1998; 97: 1029-1036.

Karim A, Ogbeide DO, Siddiqui S, Al-Khalifa IM. Prevalence of diabetes mellitus in Saudi Arabia community. Saudi Medical Journal, 2000; 21 (5): 438-442.

Kashani M, Eliasson A, Vernalis M, Costa L, Terhaar M. Improving Assessment of Cardiovascular Disease Risk by Using Family History an Integrative Literature Review. Journal of Cardiovascular Nursing, 2013; 00 (0): 00-00.

Khor GL. Ethnic Characteristic of Coronary Heart Disease Risk Factor and Mortality In Peninsular Malaysia. Asia Pacific J Clin Nutr, 1994; 3 (2): 93-98

Kumar V, Abbas AK, Aster JC. Robbins \& Cotran Pathologic Basis of Disease, 9th Edition, Elsevier Saunders, Philadelphia PA 19103 2899, USA, 2015

Kuulasmaa K, Tunstall-Pedoe H, Dobson A, Fortmann S, Sans S, Tolonen H, Evans A, Ferrario M, Tuomilehto J. Estimation of contribution of changes in classic risk factors to trends in coronary event rates across the WHO MONICA project population. Lancet, 2000;355 (9205):675-87

LaRosa JC. Lipids and cardiovascular disease: do the findings and therapy apply equally to men and women? Womens Health Issues, 1992; 2(2):102-11.

Lee J, Heng D, Chia KS, Chew SK, Tan BY, Hughes K. Risk factor and incident coronary heart disease in Chinese, Malay and Asian Indian males: the Singapore Cardiovascular Cohort study. Int J Epidemiol, 2001;30 (5):983-988

Maas AHEM, Appelman YEA. Gender differences in coronary heart disease. Neth Heart J, 2010; 18(12): 598-602.

Martín-Timón I, Sevillano-Collantes C, Segura-Galindo A, Cañizo-Gómez FJD. Type 2 diabetes and cardiovascular disease: Have all risk factors the same strength? World J Diabetes, 2014 Aug 15; 5(4): 444470 .

Milinow MR. Hyperhomocysteinemia: a common and easily reversible risk factor for occlusive arteriosclerosis. Circulation, 1990; 81: 2004-2006

Miller GJ, Miller NE. Plasma-high-density-lipoprotein concentration and development of ischaemic heart-disease. Lancet, 1975;1(7897):16-19.

Miller M, Stone NJ, Ballantyne C, Bittner V, Criqui MH, Ginsberg HN, Goldberg AC, Howard WJ, Jacobson MS, Kris-Etherton PM, Lennie TA, Levi M, Mazzone T, Pennathur S. Triglycerides and Cardiovascular Disease A Scientific Statement From the American Heart Association. Circulation, 2011; 123: 2292-2333.

Ministry of Health, Malaysia. Clinical Practice Guidelines. Management Hypertension. $4^{\text {th }}$ Edition. Kuala Lumpur, Malaysia, 2013. http://www.moh.gov.my/attachments/CPG_Management_of_Hypertensio n_4th_Edition.pdf

Nasir K, Michos ED, Rumberger JA, Braunstein JB, Post WS, Budoff MJ, Blumenthal RS. Coronary Artery Calcification and
Family History of Premature Coronary Heart Disease. Sibling History Is More Strongly Associated Than Parental History. Circulation, 2004; 110: 2150-2156.

Ng TKW, Teh CB, Vidyadaran MK, Tee ES, Thong ML, Kandiah M, Ehalid AH. A critical evaluation of high density lipoprotein cholesterol as an index of coronary artery disease risk in Malaysians. Mal J Nutr, 1997; 3: 61-70.

O'Malley PG, Jones DL, Feuerstein IM, Taylor AJ. Lack of correlation between Psychological factors and sub clinically coronary artery disease. N Eng J Med, 2000; 343 (18): 1298-1304.

Quek DL, Urn LY, Long SB. Cigarette smoking and the risk of myocardial infarction, and acute non-infarct coronary events among Malaysian women. Med J Malaysia, 1989; 44 (3): 210-223.

Roncaglioni MC, Santoro L, D'Avanzo B, Negri E, Nobili A, Ledda A, Pietropaolo F, Franzosi MG, La Vecchia C, Feruglio GA, Maseri A, on behalf of GISSI-EFRIM Investigators. Role of Family History in Patients With Myocardial Infarction An Italian Case-Control Study. Circulation, 1992, 85 (6): 2065-2072.

Scheuner MT, Setodji CM, Pankow JS, Blumenthal RS, Keeler E. Relation of familial patterns of coronary heart disease, stroke, and diabetes to subclinical atherosclerosis: The Multi-Ethnic Study of Atherosclerosis. Genet Med, 2008; 10(12): 879-887.

Shestov DB, Deev AD, Klimov AN, Davis CE, Tyroler HA. Increased risk of coronary heart disease death in men with low total and low-density lipoprotein cholesterol in the Russian Lipid Research Clinics Prevalence Follow-up Study. Circulation, 1993;88(3):846-53.

Tan AKG, Dunn RA, Yen ST. Ethnic Disparities in Metabolic Syndrome in Malaysia: An Analysis by Risk Factors. Metab Syndr Relat Disord, 2011; 9(6): 441-451.

Tanna N, Srivastava R, Tanna V, Vaishnani H. The Role of Unknown Risk Factors in Myocardial Infarction. IJBAR, 2013; 4 (6): 430434.

Weitz D, Weintraub H, Fisher E, Schwartzbard AZ. Fish Oil for the Treatment of Cardiovascular Disease. Fish Oil for the Treatment of Cardiovascular Disease. Cardiol Rev, 2010; 18(5): 258-263.

World Health Organization (WHO). Cardiovasucular Diseseas. Fact sheet $\mathrm{N}^{\circ} 317$. Updated January 2015. Available from http://www.who.int/mediacentre/ factsheets/fs317/en/

Yunus AM, Sherina M, Nor Afiah M, Rampal L, Tiew Kh. Prevalence of Cardiovascular Risk Factors in a Rural Community in Mukim Dengkil, Selangor. Malays J Nutr, 2004; 10(1): 5-11.

Zdravkovic S, Wienke A, Pedersen NL, Marenberg ME, Yashin AI, De Faire U. Heritability of death from coronary heart disease: a 36year follow-up of 20966 Swedish twins. Journal of Internal Medicine, 2002; 252: 247-254.

\section{How to cite this article:}

Haque ATME, Yusoff FBM, Ariffin MHS, Hamid MF, Hashim SRB, Haque M. Lipid Profile of the Coronary Heart Disease (CHD) Patients Admitted in a Hospital in Malaysia. J App Pharm Sci, 2016; 6 (05): 137-142. 